
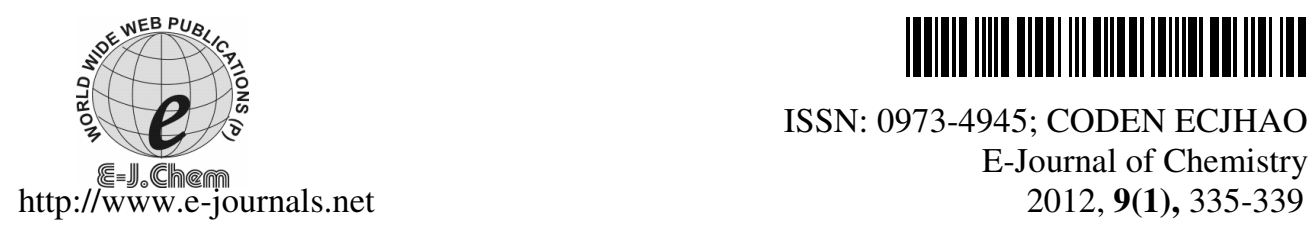

ISSN: 0973-4945; CODEN ECJHAO

E-Journal of Chemistry 2012, 9(1), 335-339

\title{
Adsorption Study of Cobalt on Treated Granular Activated Carbon
}

\author{
Y.V.HETE ${ }^{\S *}$, S.B.GHOLASE ${ }^{\S}$ and R.U.KHOPE \\ ${ }^{\S}$ Department of Chemistry, Laxminarayan Institute of Technology \\ Nagpur University, Nagpur 440 010, India \\ Department of Chemistry, Shri Shivaji Science College \\ Congress Nagar, Nagpur 440 012, India \\ yogeetahete14@gmail.com
}

Received 19 June 2011; Accepted 13 August 2011

\begin{abstract}
This study is carried out for the removal of cobalt from aqueous solution using granular activated carbon in combination with $p$-nitro benzoic acid at temperature $25 \pm 1{ }^{0} \mathrm{C}$. The adsorption isotherm of cobalt on granular activated carbon has been determined and the data fitted reasonably well to the Langmuir and Freundlich isotherm for activated carbon.
\end{abstract}

Keywords: Adsorption, Cobalt, Granular activated carbon, $p$-Nitro benzoic acid

\section{Introduction}

The rapid industrialization has caused serious repercussions such as the pollution of natural resources like groundwater. Since groundwater moves through rocks and subsurface soil, it has a lot of opportunity to dissolve substances as it moves. As a result of this pollution of water bodies becomes a major environmental problem of the modern world. Therefore, in last decades, the presence of metals in aquatic ecosystems has received widespread attention due to their potential human health risks and harmful effect to living organisms.

As cobalt is widely dispersed in the environment humans may be exposed to it by breathing air, drinking water and eating food that contains cobalt. Skin contact with soil or water that contains cobalt may also enhance exposure. It is not often freely available in the environment, but when cobalt particles are not bound to soil or sediment particles the uptake by plants and animals is higher and accumulation in plants and animals may occur. It is an animal carcinogen producing cancer at various sites. Exposure to cobalt is extremely irritating to the skin both on contact and by provoking an allergic reaction which sensitizes the skin to further contact. It is also irritating to the eyes and mucous membrane, causing severe discomfort in the nose, often leading to perforation of the nasal septum. High concentrations 
of cobalt may damage human health. When we breathe in too high concentrations of cobalt through air we experience lung effects, such as asthma and pneumonia. The threshold limit value for cobalt fume and dust exposures is $0.1 \mathrm{mg} / \mathrm{m}^{3}$ in the U.S. ${ }^{1-2}$. Treatable amount of cobalt wastes are growing need in the industrial sector to try and find ways to recover a metal through solutions using granular activated carbon $^{3-12}$. In this work, cobalt was scavenged using F $200 \mathrm{D}$ and F $300 \mathrm{D}$ containing adsorbed ligands. For this purpose $p$-nitro benzoic acid has been chosen as a organic ligand.

\section{Experimental}

Bituminous coal based Fitrasorb 200D,300D granular activated carbons were first subjected to size fractionation. Both carbons were sieved using a sieve shaker wherein the size corresponding to mesh size 16×25 (M/s Jayant Test Sieves, Mumbai) were collected for use. The sieved GAC was first stirred in boiling distilled water carefully without leading to any attrition several times until a clear leachate was obtained and then dried in an oven at a temperature of $110^{\circ} \mathrm{C}$ for $24 \mathrm{~h}$ and later cooled in a desiccators containing anhydrous $\mathrm{CaCl}_{2}$ to ensure complete removal of moisture from the carbon. A stock solution of cobalt ions was obtained by using a solution of cobalt sulphate (E. Merck). Beer's law calibration curve was established for $\mathrm{Co}^{2+}$ spectophotometrically ${ }^{13}$ to calculate concentration of experimental solutions and regression analysis of the data showed that the regression coefficient was around 0.99 .

All the chemicals used were of AR grade. A sample of $p$-nitro benzoic acid (E.Merck) was recrystallized by standard method. The experimental melting point of $p$-nitro benzoic acid $\left(241{ }^{\circ} \mathrm{C}\right)$ was checked from the literature value $\left(242^{\circ} \mathrm{C}\right)^{14}$. The sample was also characterized through determination of molecular weight by the technique of $\mathrm{pH}$ titration against standard alkali. For determining the adsorption isotherm of cobalt ion on different grades of carbon containing adsorbed ligand such as p-nitro benzoic acid, it was first essential to fix the amount of ligand on the GAC. This process of fixing of ligand on GAC was denoted as "loading of GAC". For this purpose $0.5 \mathrm{~g}$ of the GAC was taken in clean shaking bottles and $200 \mathrm{~mL}$ of the ligand solution of a specified concentration was shaken for about six hours on a mechanical shaker (Eltek Motor, Type M 56.Elektrocrats India, PVT LTD Mumbai.). The solution was then filtered off and the carbon was washed thoroughly with distilled water. This carbon was then transferred to a one liter round bottom flask and then $200 \mathrm{~mL}$ of cobalt solution at a $\mathrm{pH}=5$ were added to it. The contents were stirred for 6 hours at $25 \pm 1{ }^{\circ} \mathrm{C}$. The initial and final concentrations of the cobalt ion in $\mathrm{mg} / \mathrm{L}$ was then determined spectrophotometrically (Systronics). The concentrations of $\mathrm{Co}^{2+}$ ion were calculated using following equation obtained from calibration curve.

$$
\mathrm{C}=\frac{\mathrm{A}-0.060}{0.400}
$$

Where, $\mathrm{A}=$ Absorbance and $\mathrm{C}=$ Concentration of cobalt. The experiments were repeated to ensure reproducible results.

\section{Results and Discussion}

Equilibrium adsorption isotherms for $\mathrm{q}_{\mathrm{e}} v s \mathrm{C}_{\mathrm{e}}$ was plotted for different grades of granular activated carbon and are shown in Figure 1 and 2. 


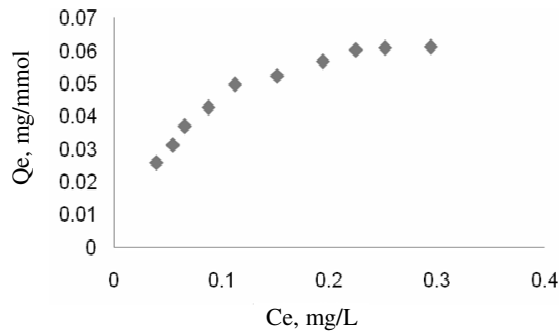

Figure 1. Adsorption isotherm system: F 200 D - $p$-nitro benzoic acid-Co ${ }^{2+}$

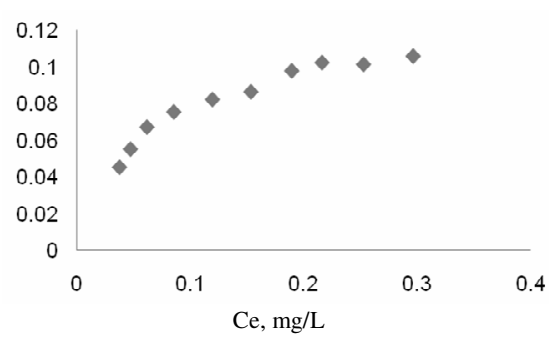

Figure 2. Adsorption isotherm system: F 300 D - p-nitro benzoic acid-Co ${ }^{2+}$

The amount of cobalt on the ligand adsorbed on the GAC was determined using the equation:

$$
\mathrm{q}_{\mathrm{e}}=\left(\mathrm{C}_{\mathrm{o}}-\mathrm{C}_{\mathrm{e}}\right) \times \frac{\mathrm{V}}{\mathrm{W}}
$$

Where, $\mathrm{q}_{\mathrm{e}}=$ Concentration of cobalt on the ligand loaded GAC in $\mathrm{mg} / \mathrm{millimoles}$ of ligand, $\mathrm{C}_{\mathrm{o}}=$ Initial concentration cobalt in solution in $\mathrm{mg} / \mathrm{L}, \mathrm{C}_{\mathrm{e}}=$ Final concentration of cobalt in solution in $\mathrm{mg} / \mathrm{L}, \mathrm{V}=$ Volume of solution in litres, $\mathrm{W}=$ Millimoles of the ligand actually present on GAC $(0.5 \mathrm{~g})$. It is observed from the result in Table 1 that cobalt adsorption follows the trend F 300 D > F 200 D

Data of equilibrium isotherms was tested for adherence to both Langmuir and Freundlich models. As per Langmuir theory, the saturated value is that beyond which no further sorption can take place. The saturated monolayer can then be represented by

$$
\mathrm{q}_{\mathrm{e}}=\mathrm{Q}^{0} \mathrm{bx} \frac{\mathrm{C}_{\mathrm{e}}}{1+\mathrm{bC}_{\mathrm{e}}}
$$

The linearised form of Langmuir isotherm is

$$
\frac{1}{\mathrm{q}_{\mathrm{e}}}=\frac{1}{\mathrm{Q}^{0} \mathrm{~b}} \times \frac{1}{\mathrm{C}_{\mathrm{e}}}+\frac{1}{\mathrm{Q}^{0}}
$$

Where $\mathrm{Q}^{\circ}$ and $\mathrm{b}$ are Langmuir constants. Freundlich equation is on the other hand represented by

$$
\mathrm{q}_{\mathrm{e}}=\mathrm{kC}_{\mathrm{e}}^{1 / \mathrm{n}}
$$

The above equation may be linearised as

$$
\log \mathrm{q}_{\mathrm{e}}=\log \mathrm{k}+\frac{1}{\mathrm{n}} \beta \log \mathrm{C}_{\mathrm{e}}
$$

Where $\mathrm{k}$ and $1 / \mathrm{n}$ are Freundlich constants. Figure 3 to 6 illustrates the plot of Langmuir and Freundlich isotherms for F $200 \mathrm{D}$ and F 300 D. The plots of $1 / \mathrm{q}_{\mathrm{e}} v s 1 / \mathrm{C}_{\mathrm{e}}$ were found to be linear indicating the applicability of Langmuir model. The parameters $\mathrm{Q}^{\circ}$ and $\mathrm{b}$ are Langmuir constants relating to the sorption capacity and adsorption energy respectively. The intercept and slope of the liner plots of $\log \mathrm{q}_{\mathrm{e}} v s \log \mathrm{C}_{\mathrm{e}}$ and of $1 / \mathrm{q}_{\mathrm{e}} v s 1 / \mathrm{C}_{\mathrm{e}}$ under given set of experimental conditions provide values of $\mathrm{k}, 1 / \mathrm{n}, \mathrm{Q}^{\mathrm{o}}$ and $\mathrm{b}$ respectively. The corresponding Freundlich and Langmuir constants obtained are listed in Table 1 . The values of $k$ and $\mathrm{Q}^{\circ}$ for F 300 D carbon- $p$-nitro benzoic acid- $\mathrm{Co}^{2+}$ system were greater than those for $\mathrm{F} 200 \mathrm{D}$ carbon- $p$-nitro benzoic acid-Co ${ }^{2+}$ system, indicating the superiority of the former for this sorption process. 


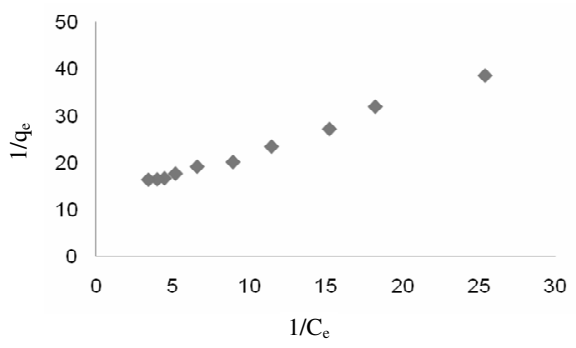

Figure 3. Langmuir adsorption isotherm System: F 200 D - p-nitro benzoic acid$\mathrm{Co}^{2+}$

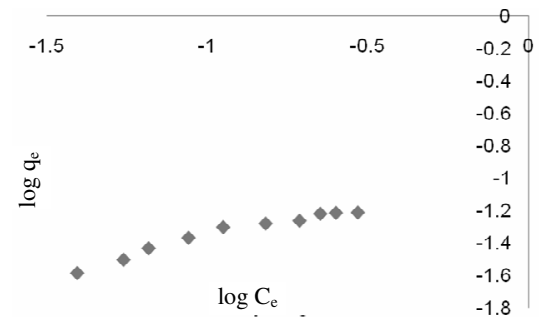

Figure 5. Freundlich adsorption isotherm System: F 200 D - p-nitro benzoic acid- $\mathrm{Co}^{2}$

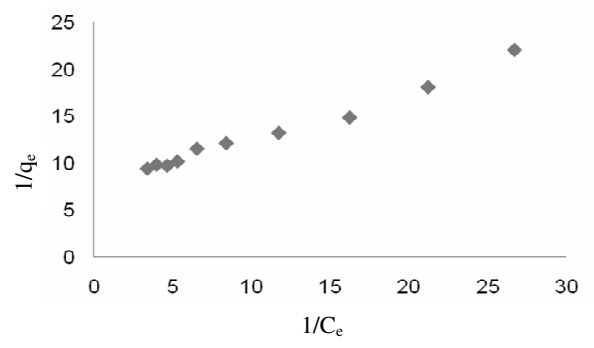

Figure 4. Langmuir adsorption isotherm System: F 300 D - p-nitro benzoic acid$\mathrm{Co}^{2+}$

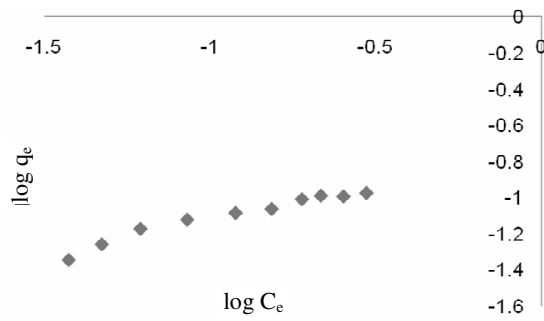

Figure 6. Freundlich adsorption isotherm System: F $300 \mathrm{D}$ - p-nitro benzoic acid-Co ${ }^{2+}$

Table 1. Isotherm constants

\begin{tabular}{ccccccc}
\hline S.No & System & $\begin{array}{c}\text { Langmuir } \\
\mathrm{Q}^{\mathrm{o}}\end{array}$ & $\begin{array}{c}\text { Constants } \\
\mathrm{b}\end{array}$ & $\begin{array}{c}\text { Freundlich } \\
\mathrm{k}\end{array}$ & $\begin{array}{c}\text { Constants } \\
1 / \mathrm{n}\end{array}$ & $\begin{array}{c}\mathrm{q}_{\max } \\
\mathrm{mg} / \mathrm{m} . \mathrm{mol}\end{array}$ \\
\hline 1 & $\begin{array}{c}\text { F 200 D- } p \text {-nitro } \\
\text { benzoic acid-Co }\end{array}$ & 0.0828 & 11.628 & 0.1116 & 0.422 & 0.0612 \\
2 & $\begin{array}{c}\text { F 300 D - } p \text {-nitro } \\
\text { benzoic acid-Co }\end{array}$ & 0.1315 & 14.8226 & 0.1803 & 0.384 & 0.1059 \\
\hline
\end{tabular}

Plot of $\log \mathrm{q}_{\mathrm{e}} v s \log$ Ce was fairly linear showing validity of Freundlich equation also over a rang of concentrations employed for the ligands as shown in Table 2 all experimental solutions were analyzed using the equation found by regression analysis of absorbance concentration data. In present work order of adsorption followed the trend, GAC- F 300 D > GAC - F 200 D.

Table 2. Regression analysis data

\begin{tabular}{|c|c|c|c|c|}
\hline S.No. & System & Type of adsorption & Equation & Reg Coeff \\
\hline 1 & $\begin{array}{l}\text { F } 200 \mathrm{D} \text { - } p \text {-nitro } \\
\text { benzoic acid-Co }\end{array}$ & $\begin{array}{l}\text { Langmuir adsorption } \\
\text { isotherm }\end{array}$ & $\begin{aligned} \mathrm{y}= & 1.038 \mathrm{x}+ \\
& 12.07\end{aligned}$ & 0.992 \\
\hline 2 & $\begin{array}{l}\text { F } 300 \text { D - } p \text {-nitro } \\
\text { benzoic acid-Co }\end{array}$ & $\begin{array}{l}\text { Langmuir adsorption } \\
\text { isotherm }\end{array}$ & $\begin{aligned} y= & 0.513 x+ \\
& 7.604\end{aligned}$ & 0.983 \\
\hline 3 & $\begin{array}{l}\text { F } 200 \text { D - p-nitro } \\
\text { benzoic acid-Co }{ }^{2+}\end{array}$ & $\begin{array}{c}\text { Freundlich adsorption } \\
\text { isotherm }\end{array}$ & $\begin{array}{c}y=0.422 x- \\
0.952\end{array}$ & 0.950 \\
\hline 4 & $\begin{array}{l}\text { F } 300 \text { D - } p \text {-nitro } \\
\text { benzoic acid-Co }{ }^{2+}\end{array}$ & $\begin{array}{c}\text { Freundlich adsorption } \\
\text { isotherm }\end{array}$ & $\begin{aligned} y= & 0.384 x- \\
& 0.744\end{aligned}$ & 0.951 \\
\hline
\end{tabular}




\section{Conclusion}

From the above studies, it is clear indicated that granular activated carbon could function very effectively in scavenging metal ions from aqueous solution. The adsorption isotherms of the cobalt on different grades of carbon loaded with p-nitro benzoic acid clearly shows that F 300 D carbon adsorbs cobalt to a greater extent as compared to F $200 \mathrm{D}$ carbon. Adsorption was found to be in good agreement with Langmuir isotherm which indicates mono layer adsorption. However these methods can be optimized further by using oxidizing agents, study of which is in progress.

\section{References}

1. Mukharjee A.G, Envirinmental Pollution and Health Hazards; Causes and Control, in: Galgotia S, (Ed), New Delhi, 1986.

2. Dara S S, A text book of environmental chemistry and pollution control, in: Chand S, Company Ltd (Ed), New Delhi, 2002, 215.

3. Paajanen A, Lehto J, Sataapakka T and Morneau J P, Sep Sci Technol., 1997, 32, 813.

4. $\quad$ Netzer A and Hughes D E, J Water Res., 1984, 18(8), 927-933.

5. Corupeioglu M O and Huang C P, J Water Res., 1987, 21(9), 1031-1044.

6. Rivera, Utrilla J and Garcia M A F, Carbon, 1987, 25, 645.

7. Yupeng Guo, Jurui Qi, Shaofeng Yang, Kaifeng Yu, Zichen Wang and Hongding X U, 2003, 78(1), 132-137.

8. Khope R U, Halmare S S and Natarajan G S, Asian J Chem., 2004, 16(2), 751-754.

9. Abiola Olusegun K and Otaighe J O E, Int J Electrochem Sci., 2008, 3, 191-198.

10. Islam M and Patel R K, J Hazardous Mater., 2007, 143, 303-310.

11. Daifullah A A M, Yakout S M and Elreefy S A, J Hazardous Mater., 2007, 62, 1-32.

12. Meena A K, Rajagopal C, Kiran C R and Mishra G K, J Sci Ind Res., 2010, 69, 449-453.

13. Vogel A I, Quantitative inorganic analysis, $4^{\text {th }}$ Ed., Longman Group Ltd., England, $1978,739$.

14. Rodd E H, Chemistry of Carbon Compounds, Elsevier Publishing Company, N.Y.3B, $1956,769$. 


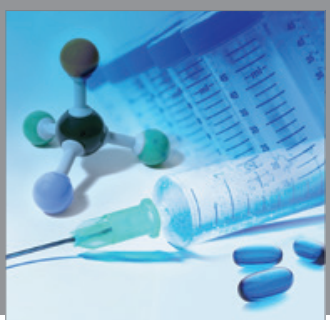

International Journal of

Medicinal Chemistry

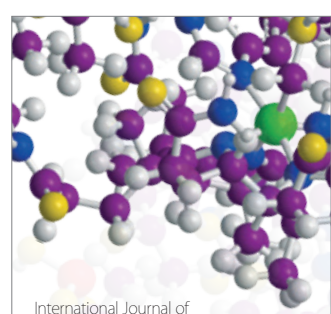

Carbohydrate Chemistry

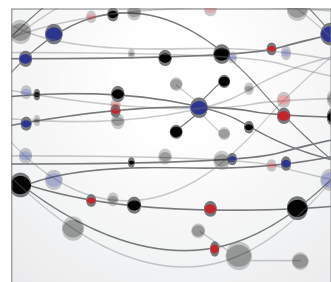

The Scientific World Journal
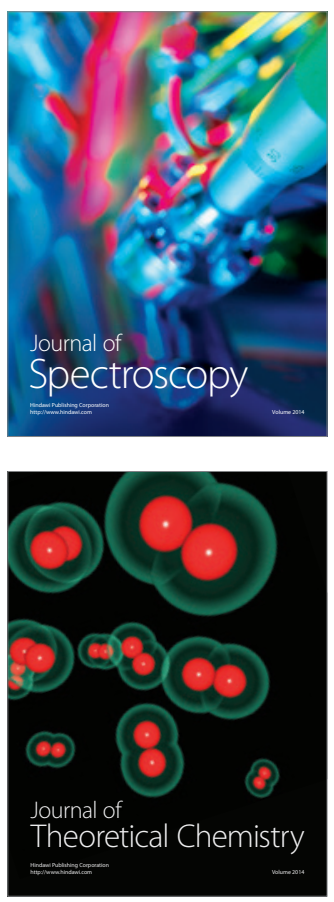
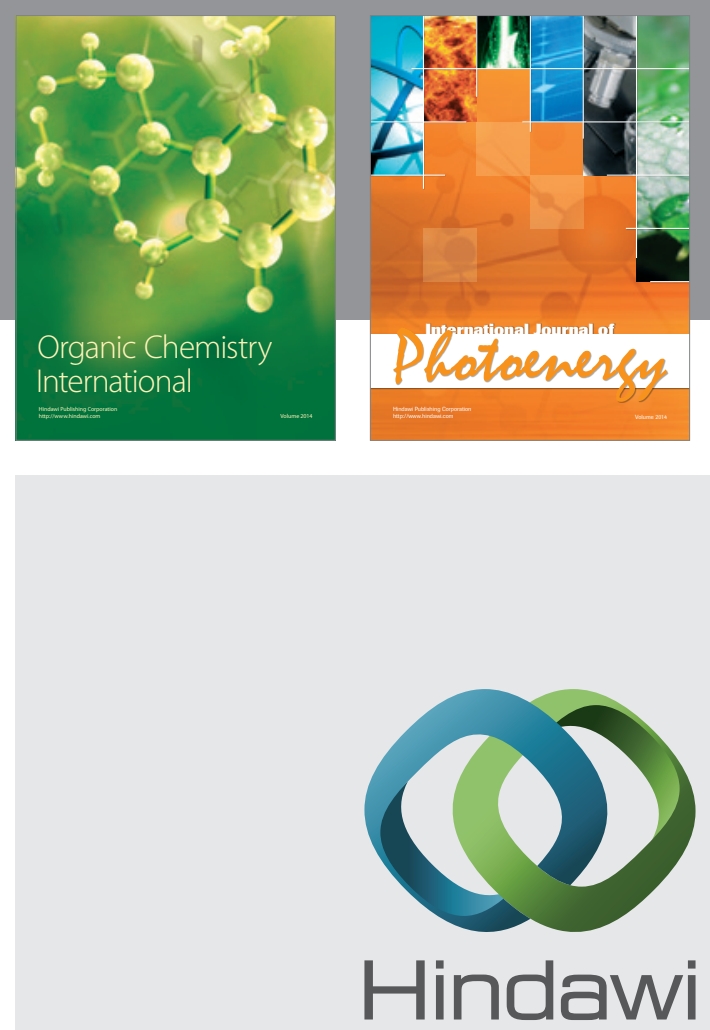

Submit your manuscripts at

http://www.hindawi.com
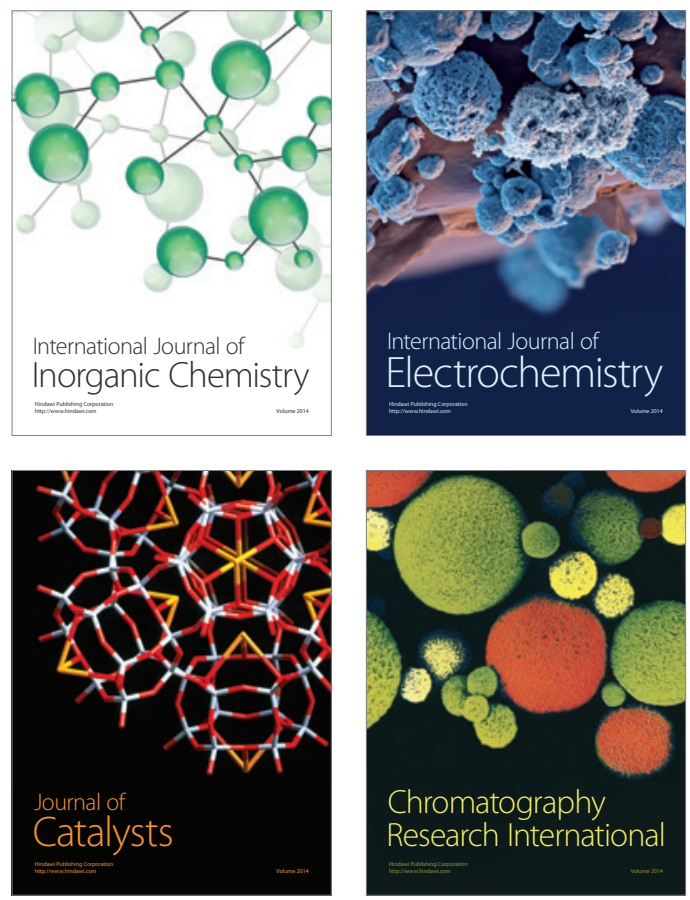
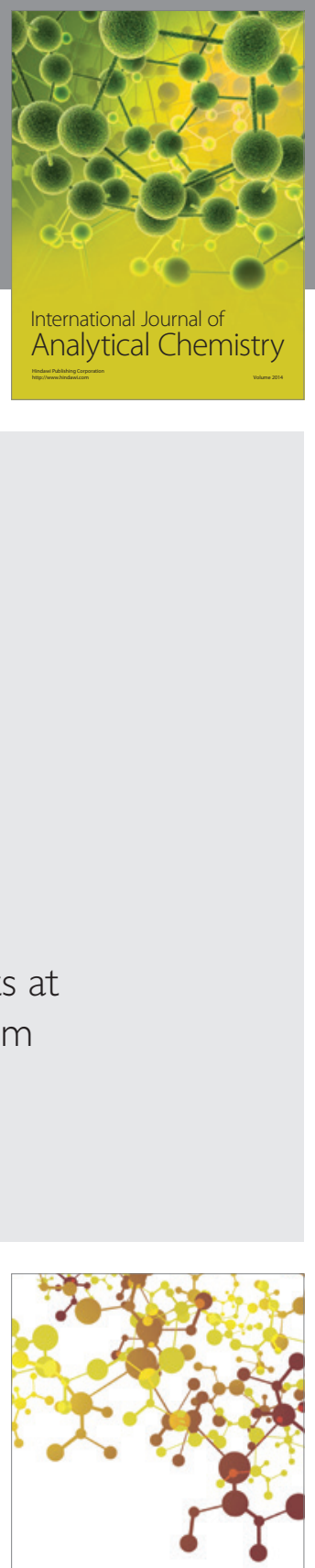

Journal of

Applied Chemistry
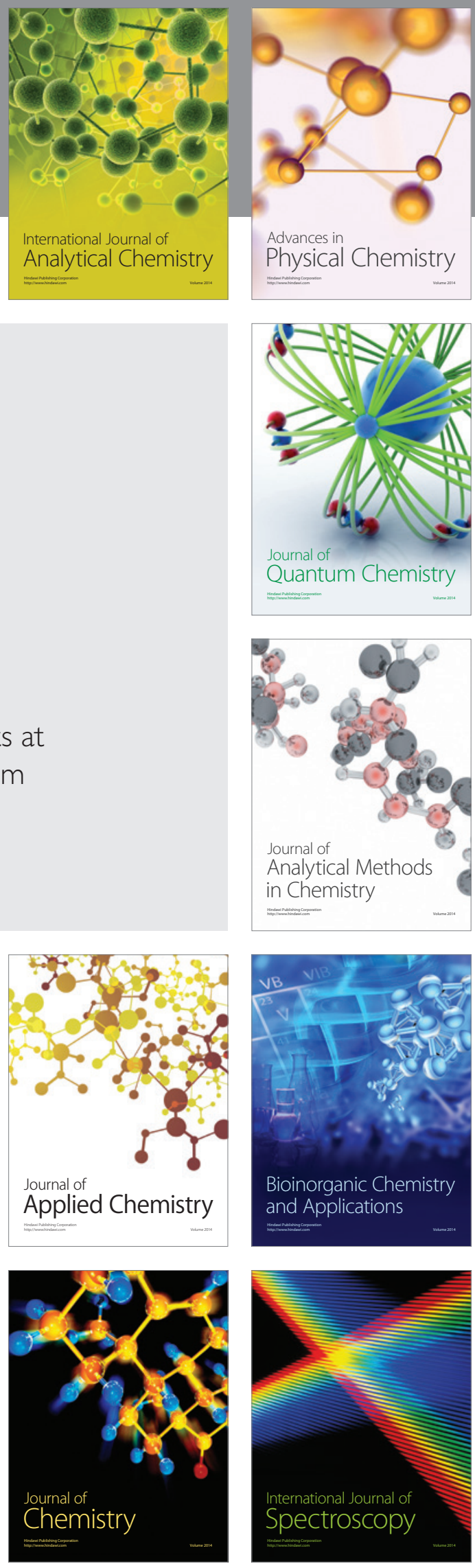